the house, so that he could personally supervise every detail of the arrangements, and for two years this became his principal occupation.

A special feature of the Institution was to be the Repository or Model-room in which working models of new inventions were to be exhibited. There were to be fireplaces, stoves and kitchen utensils of the latest design. A complete kitchen was to be equipped, from which meals would be served to the proprietors. Workshops would be established and classes held for the instruction of artisans and mechanics. The speedy introduction of all useful mechanical inventions and improvements was to be one of the two principal objects ; the other was the application of science to the improvement of arts and manufactures, and for this purpose a lecture room and laboratories would be provided, professors and lecturers engaged, courses of philosophical lectures would be given and chemical and other experiments carried out. For the management of the Institution there were to be committees of managers to govern and direct, and 'visitors' to inspect and audit, responsible to the proprietors, whose interest was hereditary.

For a time the efforts of the early managers met with much success. The ninth Earl of Winchilsea became the first president; the nobility and gentry, the philanthropic and the learned, gave their support as proprietors or subscribers. The lecture theatre, now famous as one of the best for its purpose in existence, was built, the model room, laboratories and workshops constructed and equipped, and the library and reading-rooms opened to the proprietors. Dr. Thomas Garnett, from Anderson's Institution in Glasgow, was engaged as the first professor, and courses of lectures were begun.

This was the Royal Institution as it was originally conceived, and although there have been great changes, those who know it will recognize much that has survived to the present day. It was Rumford's plan, and in the early years his ideas were closely followed. $\mathrm{He}$ is rightly regarded as the founder; although by some a share at least of the honours has been claimed for Sir Thomas Bernard.

After a time, however, differences of opinion arose. Rumford quarrelled with Prof. Garnett, and he fell out with some of the other managers, who found him dictatorial and overbearing. Not all of them were in sympathy with his philanthropic ideas or believed that the poor and the working classes in Britain would respond to the methods he had found successful in Bavaria. Moreover, the plan for the Institution proved too ambitious and expensive and had to be curtailed. Rumford began to lose interest; he went off to the Continent again, intending to return; but, in fact, he stayed in Paris to marry the widow of the great French chemist Lavoisier.

The control of the Royal Institution fell into other hands. The new managers quietly dropped the classes for mechanics, the cooking and kitchen economy, and other features of Rumford's plan, and endeavoured to popularize the establishment with those to whom it looked for financial support by arranging courses of lectures on popular science, literature and the arts. Sir Joseph Banks in London grumbled by letter to Rumford regretting his absence, telling him that the Institution was "now entirely in the hands of the profane" and declaring that he would have nothing more to do with it.

But the changes which now took place were due not so much to acts of the management as to the activities and growing reputation of Humphry Davy.
Before he left England, Rumford had engaged this young man from Bristol as lecturer in chemistry. Thomas Young had succeeded Garnett, and for a time Young and Davy worked together. Later, Davy became the professor of chemistry, and it is well known how his gifts as a lecturer and his brilliant researches on the chemical action of electricity established both his own reputation and that of the Institution. Scientific research and exposition became the order of the day.

This alteration of purpose was frankly recognized by an Act of Parliament in 1810, which amended the constitution of the Institution, extending its objects to include the "promotion of chemical science by experiments and lectures" and the "diffusion and extension of useful knowledge in general", and substituting for the hereditary proprietors, who were compensated and dispossessed, a body of elected members. Constitutionally, the Royal Institution as we know it to-day dates from the Act of 1810; but its character and traditions were established by the brilliance of Humphry Davy, to be maintained and enlarged by the genius of his assistant and successor, Michael Faraday.

At this hundred and fiftieth anniversary, however, we celebrate the founder, Benjamin Thompson, Count Rumford. He made probably his greatest contribution to its success when he brought Humphry Davy to work in his Institution; and if it is some. thing of a changeling from the establishment he originally intended, none will now deny him credit for the importance of his achievement or its significance in the history of science.

\section{FOREST RESOURCES OF THE WORLD}

A SMALL booklet has recently been issued by the Food and Agriculture Organisation of the United Nations, Diffigion of Forestry, entitled "Forest Resources of (AT/ World" (Washington, D.C., 1948). This report is of first importance and interest, and discloses the steps which have been taken to have a regl inteftitory of the world's forestry resources pfinfred, a piece of work far more difficult of afhiefement than might be supposed. This difficulty is due to the fact that a considerable proportion of the forests of the world are still without any really proper and efficient management. Consequently, any figures obtained on the subject of the abundance or otherwise of their several resources can, in certain cases, be accepted only with reserve.

The report commences with the question as to whether or not man will be compelled to resign himself to a perpetual shortage of forestry products. To this the report's answer is ' $\mathrm{No}$ ', and this reply applies to a still larger population than at present exists. It will be of interest to follow the argument which, of necessity, must be based to a considerable extent on the still untapped forests of the world.

From earliest times a large section of the world's population has depended on the forest-at first for fuel only, then for timber for house construction, farm implements and so forth. The introduction of more modern forms of building, it was said, would see the importance of timber decrease and, therefore, the people's corresponding dependence on the forest. The reverse has been the case. The modern industrial age has brought with it new demands on wood for direct use in manufacturing industries and for 
making the crates and boxes which protect these products in transit. The extraordinary, and certainly not foreseen, development in the uses of wood pulp during the past century has made the forest the primary source of most of the world's paper and of a substantial proportion of its textiles. Wood chemistry is constantly developing entirely new products derived from wood. How great are these increased demands and what bearing have they on the existing forests and possibly newly created forests in the world? For one thing, there is no longer the sharp distinction of utilization which form. erly existed between the conifers and the hardwoods. Hardwoods are now converted and used in industry for purposes for which originally only the conifer was considered suitable. This is to the good; and modern machinery and research have made it possible to utilize some of the hardwood species of the mixed tropical forests previously regarded as valueless for commercial and, therefore, sale purposes. Incidentally, this will facilitate the sylvicultural working and management of some of these forests. The other advance which it is imperative should be made is to put an end, in the interests of the world community and not only of those of one particular country, to lumbering in all its forms, with its aftermath so often of bad erosion and destruction, the starting of fires in the debris on the lumbered area, and their spreading into valuable standing forests and often into townships and villages. In this respect the waste in some parts of the world has been enormous; and yet the method still continues in the interests of the few. Less spectacular, but equally serious, is the continuing practice of the removal of forest growing on true forest soils in order to make room for poor and unproductive farms; in the tropics vast areas of forest have been degraded or entirely destroyed by the cycle of shifting cultivation and annual firing followed by excessive grazing, leading to the production of desert condition. With the balance of Nature upset, anything may happen: erosion and loss of valuable top-soil, lowering of water-levels in the soil, floods and devastation caused by such at the lower land-levels.

The first essential steps to ensure the future forest reserves is for the nations to get together and determine the measures required to stop general forest destruction throughout the world. The forester responsible for the well-being and management of the respective forest areas, and the timber and other merchants who extract the varied commodities from the forest and take them to the market, will then all be in a better position to gauge the maintenance of the forest resources position.

A first attempt at a solution was made by Dr. Raphael Zon and Mr. William A. Sparhawk in the United States immediately after the First World War. Their publication of 1922 was followed up by further efforts on the part of Finland and Sweden and by the International Institute of Agriculture at Rome, which published estimates supplied by national Governments in year-books between 1933 and 1948. In 1946, available information on the world's forests was summarized in a report submitted to the second session of the Conference of the Food and Agriculture Organisation under the title "Forestry and Forest Products-World Situation 1937-1946". In the same year, Sir Hugh Watson made a study which appeared in the "British Empire Forestry Handbook".
All these attempts suffered from the inevitable chief drawback-the lack of reliable forest-inventory information, coupled with the lack of common forestry definitions.

How far has this deterrent affected the present publication? At the first session of the Conference of the Food and Agriculture Organisation in the autumn of 1945, the need for knowledge of the forest resources of the world was recognized. Later, it was decided to issue a draft questionnaire to all countries, only questions essential to an appraisal of the forestry situation in each country being included. The preparation of such a document would not appear to offer much difficulty. But the reality was far different. Quite apart from the diversity of forestry definitions, all sorts of other difficulties had appeared, and the final form of the questionnaire was not approved until the meeting of the third session of the Conference at Geneva in August 1947. Even in that final form it was obvious that difficulties, if not ambiguities, remained; for example, for tropical countries, the filling up of such a form for a province in India, with its regulated forest-management extending over a period of eighty years, as compared with one of the South American States where forestry management has scarcely made an appearance.

Herein lies the danger of an attempt to draw up inventories of forestry resources which are based on world figures designed to form a basis for world production and for utilization for a world population, the growth of which in relation to the use of the forest resources available cannot be correlated. A census of the total world population is possible. But attempts at a similar census of the world's forestry resources, given our present actual knowledge of many of the last remaining forestry areas, as, for example, in the Latin American States, or the large area of forest in northern Russia and Siberia, must inevitably detract from the value of world figures. On the other hand, those figures obtainable for the comparatively small area of forest under a high or even modified forestry management will prove sufficiently accurate; but it is dangerous to take estimates based on such figures and apply them elsewhere to forests of which little is known. This has failed before. It is for similar reasons that calculations of the growth and volume of timber to be derived from plantations made on previously bare unafforested lands are likely to be incorrect.

Nevertheless, both the work and the information we have in this booklet are invaluable. At last the difficulties have been clearly seen and thoroughly grasped. Such items as land classification, classification of production forests, land ownership and volume of growing stock, all of them apparently simple divisions of the subject, produced divergencies of interpretation and meaning. Official statements respecting the forest resources of 101 countries and non-self-governing territories were received up to the date of publication. Additional questionnaires were expected, but the widespread interest aroused by the inquiry was considered to justify the publication of the present booklet. The tabular statements are ten in number and are entitled, respectively: response to inventory questionnaire; forested areas of the world; classification of productive forests; land classification; classification of productive forests, contd.; ownership of productive forests; growing stocks in accessible productive forests; average annual growth and annual drain for all species, for conifers only, for broad-leaved forests, respectively. 
From the figures obtained, the authors of the report state that the forests of the world are capable of providing "reasonably adequate supplies" to a population larger than now exists. "But," they write, "the provision of such supplies will entail treatment of all productive forests as renewable crops, opening up of forests which are not yet accessible, and cessation of the widespread devastation of forests which, in this twentieth century, still continues."

If this is to come about, Governments, and their responsible ministers, finance members and treasuries, will have to regard the forest and its management as a very different proposition from that envisaged in the past. With the Governments responsible must be included large masses of the populations existing on the globe to-day; for without their intelligent co-operation in forest protection and management, inventories of forest resources may prove misleading and even dangerous.

E. P. Stembing

\section{NON-UNIFORMITY OF THE EARTH'S ROTATION AND GEOMAGNETISM}

\section{By Prof. W. M. ELSASSER University of Pennsylvania}

$\mathrm{T}$ HE existence of a secular deceleration of the earth's angalar velocity at a rate

$$
\lambda \omega / d t=-2.5 \times 10^{-22} \text { sec. }^{-2}
$$

has long been established from astronomical data1. The glassicel work of G. H. Darwin and of Jeffreys, culnninating in Jeffreys's computation of the frictional torque of the oceanic tide, seemed to have settled the theoretical aspects of the problem ${ }^{2}$. Later, de Sitter ${ }^{3}$ and Spencer Jones ${ }^{4}$ re-investigated the astronomical data. The value (1) is based on data from ancient eclipses and represents the average deceleration over the last two thousand years. Observations of the longitude of the moon, sun and planets over the past two hundred and fifty years show that the mean deceleration during this time was smaller than (1) - according to de Sitter 60 per cent, according to Spencer Jones 35 per cent of (1). Both the ancient and modern data seem trustworthy, and the conclusion is that a change in deceleration during the historical age is most probably real. Quite recently, it has been necessary to reopen the question as new geophysical information has become available. It can now be said that in all probability the deceleration of the earth is produced by two independent agencies: the oceanic tide, and a still very obscure effect in the earth's liquid core. While nothing is as yet known about the dynamics of motions in the core, there is good reason for believing that an appreciable fraction of the retarding torque operates in the core rather than in the oceans. This is perhaps close to the original ideas of Darwin, but the observations that lead to this conclusion are novel.

Let us first give a brief idea of the mechanics of the deceleration. We shall ignore the small solar tide as compared to the lunar tide. The angular momentum of the system earth-moon must be conserved. Darwin and Jeffreys have shown that the orbital motion of the moon takes up the angular momentum lost by the earth; the moon gradually recedes from the earth. Now the ratio of energy to angular momentum for the earth's rotation is $\frac{1}{2} \omega_{e}$; the same ratio for the moon's orbital motion is $-\frac{1}{2} \omega_{m}$. But $\omega_{e} / \omega_{m}=28$, and it follows that per unit angular momentum transmitted to the moon, only $1 / 28$ of the rotational energy of the earth is transmitted; the remainder must be used up by friction or other transformations of energy in the earth. The frictional forces produce a couple that retards the earth, and at the same time a force acts on the moon, tending to push the latter away from the earth. One of the more gratifying features of this theory is the fact that the observed deceleration is of the right general order to account for a gradual removal of the moon from an original position very close to the earth to its present distance during the known life-time of the earth.

The new evidence arises from rather unexpected quarters ; it is based on geomagnetic observations. As we have endeavoured to show ${ }^{5}$, the secular variation of the geomagnetic field can be explained by means of motions of the matter in the earth's fluid metallic core. Such motions induce electric currents in the core, of magnitude $I=\sigma v \times B$, where $\sigma$ is the conductivity, $v$ the velocity of the fluid, $B$ the existing magnetic field. Bullard ${ }^{6}$ has recently come to identical conclusions; he has, moreover, applied these principles to a study of the secular variation, with prom. ising results. In general, an electromagnetic field in the presence of internal motions in a fluid con. ductor is non-conservative; energy is being exchanged between the field and the motion of the fluid. On the other hand, it can be shown ${ }^{5}$ that so long as a parcel of the fluid moves without deform. ation, or if its deformation is negligible, it carries its electric currents and magnetic field with it unchanged except for the free decay of the currents. One immediate consequence of this is the fact that the observed irregular magnetic field rotates with the earth. Another important consequence will be indicated below.

We have recently come into possession of a most remarkable set of world-wide maps of the secular geomagnetic variation, constructed by Vestine and his collaborators". These are based on an exhaustive evaluation of magnetic data and cover the period 1912-42 in intervals of ten years. The maps show that there are a number of centres of the secular variation scattered about the earth; these centres undergo rapid changes of intensity and also displacements of their position. The similarity of these maps and of ordinary weather charts is amazing, and there is no better way of conveying the idea that the secular variation owes its origin to fluid motions in the core than a contemplation of these maps. There are two independent ways in which the velocity of the fluid can be estimated, first by direct inspection of the displacement of the centres, and secondly from the rate of change of the field, using the electromagnetic theory 5,6 . Both methods give velocities of about $0 \cdot 1-1 \mathrm{~mm}$./sec. The most interesting feature, however, exhibited by these maps is a general drift of the whole pattern of the secular variation in the direction from east to west. It is difficult to assign an exact numerical value to this drift motion, since it is superposed upon the irregular displacement of the centres and is of the same order of magnitude as the latter. In order to have a convenient figure, we may estimate a value of $0.5 \%$ year, which at the equator of the core represents a linear velocity of 